\title{
NAVICULO-CUNEIFORM SYNOSTOSIS
}

\author{
HeNRY L. J. LUSBY, LONDON, ENGLAND
}

From the Department of Surgery, Hammersmith Hospital, London

\begin{abstract}
Abnormal coalition between tarsal bones is well recognised as a cause of pain in the foot. Not all such coalitions give trouble. In the case recorded below there were radiological signs suggestive of a synostosis but the patient had never had flat foot nor had he ever had pain in his feet or legs.

Case report-The patient was a middle-aged man who sustained a fracture of the medial malleolus in an accident. When the radiographs were examined one noticed, apart from the fracture, a small flake-like piece of bone on the dorsal aspect of the navicular bone. It did
\end{abstract}

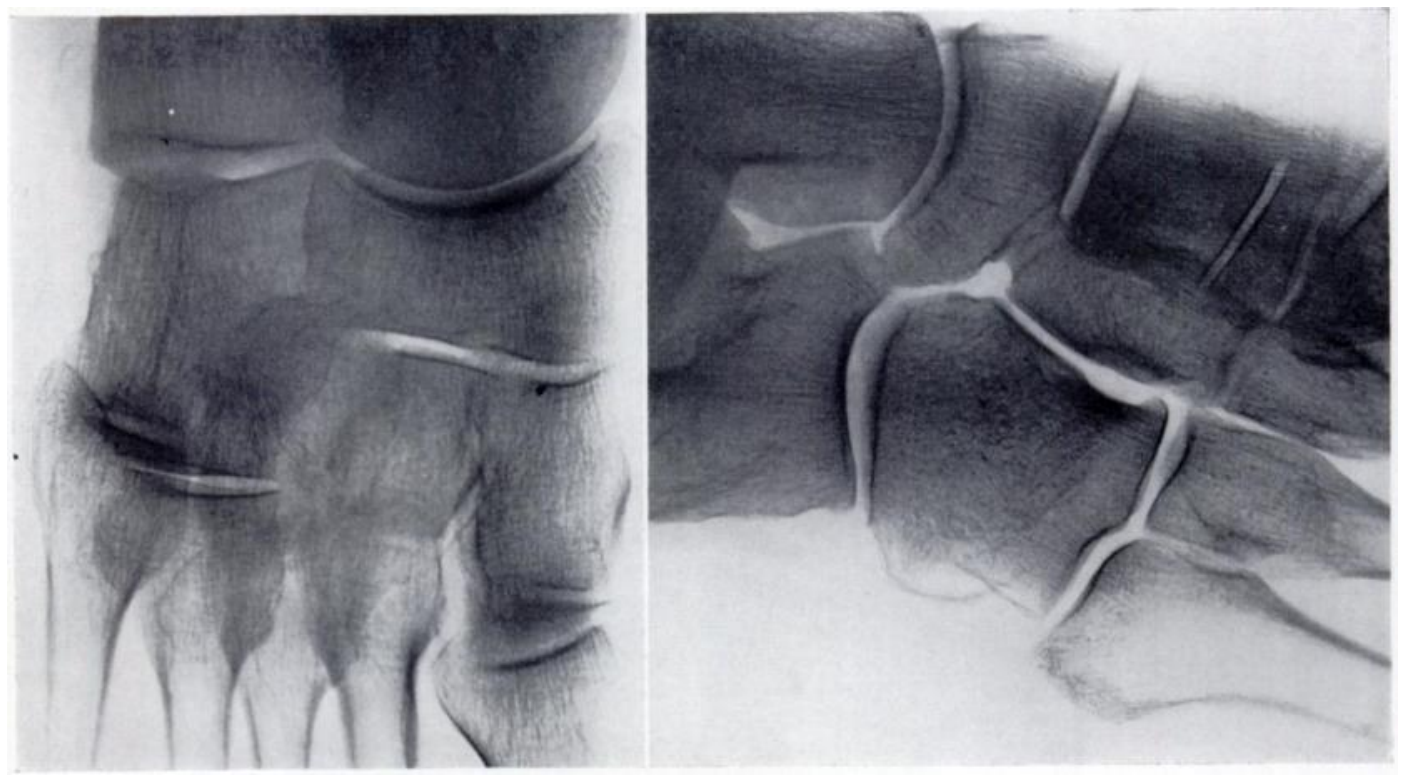

FIG. 1

not seem to have the appearance of a chip fracture, and further radiographs of the foot were obtained to see if indeed a synostosis were present. These showed a solid bar of bone connecting the navicular bone to the lateral cuneiform bone (Fig. 1). There was no abnormality in the other foot.

Comment - No other report of such a synostosis has been found. 